\title{
Deformation Behavior of Directionally Solidified Mg-4 wt.\% Zn Alloy during Hot Compression Experiment
}

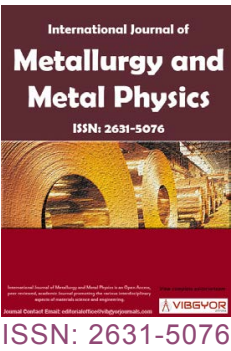

\section{Hongmin Jia* and Jianxiu Chang}

School of Materials Science and Engineering, Xi'an Shiyou University, China

\begin{abstract}
The hot deformation behavior of directionally solidified Mg-4 wt.\% Zn alloy was investigated by compression tests at temperatures of $150{ }^{\circ} \mathrm{C} \sim 300{ }^{\circ} \mathrm{C}$ and strain rates of $0.01 \mathrm{~s}^{-1} \sim 10 \mathrm{~s}^{-1}$. The results show that the flow stress is influenced by strain rate, deformation temperature and true strain. The constitutive equation of the directionally solidified alloy is determined and can be expressed as:

$\dot{\varepsilon}=1.049 \times 10^{8}[\sinh (0.006 \sigma)]^{7.778} \exp \left(-1.091 \times 10^{4} / T\right)$. The flow stress model based on the regression analysis is founded to predict the flow behavior of directionally solidified Mg-4 wt.\% Zn alloy during hot deformation, and result show that the model has a great agreement with experimental dates. Besides, based on microstructural evolution observation, directionally solidified Mg-4 wt.\% Zn alloy exhibits good hot workability at higher temperature and lower strain rate, and the effect of deformation temperature is more obvious than strain rate on crystallization during hot deformation.
\end{abstract}

\section{Keywords}

Mg alloy, Directional solidification, Hot workability, Deformation behavior, Microstructural evolution

\section{Introduction}

Mg alloys have many potential applications in aerospace, automotive and portable electronic fields due to low density, good castability and high specific strength [1-4]. Recently, Mg alloys have also been the focus of degradable implant research for excellent biocompatibility in human body and no signs of local or systemic toxicity [58]. Although much progress has been made for developing biodegradable $\mathrm{Mg}$ alloys in the last decades, a number of fundamental challenges remain: (1) Many alloys tested so far are initially developed for industrial uses, typical examples are $\mathrm{Mg}-\mathrm{Zn}-\mathrm{Al}$ and $\mathrm{Mg}$-RE alloys, inside which, Al and rare earth elements are toxic [9-11]. (2) Matching the geometry of bone graft to that of affected area is necessary in order to obtain satisfactory results. But the formability of $\mathrm{Mg}$ alloys are quite poor, and it is difficult to deform $\mathrm{Mg}$ alloys into components at low temperature due to their hexagonal close packed (HCP) structure and low stacking fault energy [12-14].

Zinc being a biocompatible element [15], MgZn alloy has been very attractive for implant appli-

*Corresponding author: Hongmin Jia, School of Materials Science and Engineering, Xi'an Shiyou University, Xi'an 710065, China, Tel: +86-29-88382536

Accepted: February 18, 2020; Published: February 20, 2020

Copyright: (C) 2020 Jia et al. This is an open-access article distributed under the terms of the Creative Commons Attribution License, which permits unrestricted use, distribution, and reproduction in any medium, provided the original author and source are credited.

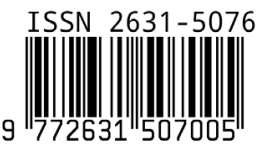

Jia and Chang. Int J Metall Met Phys 2020, 5:044 


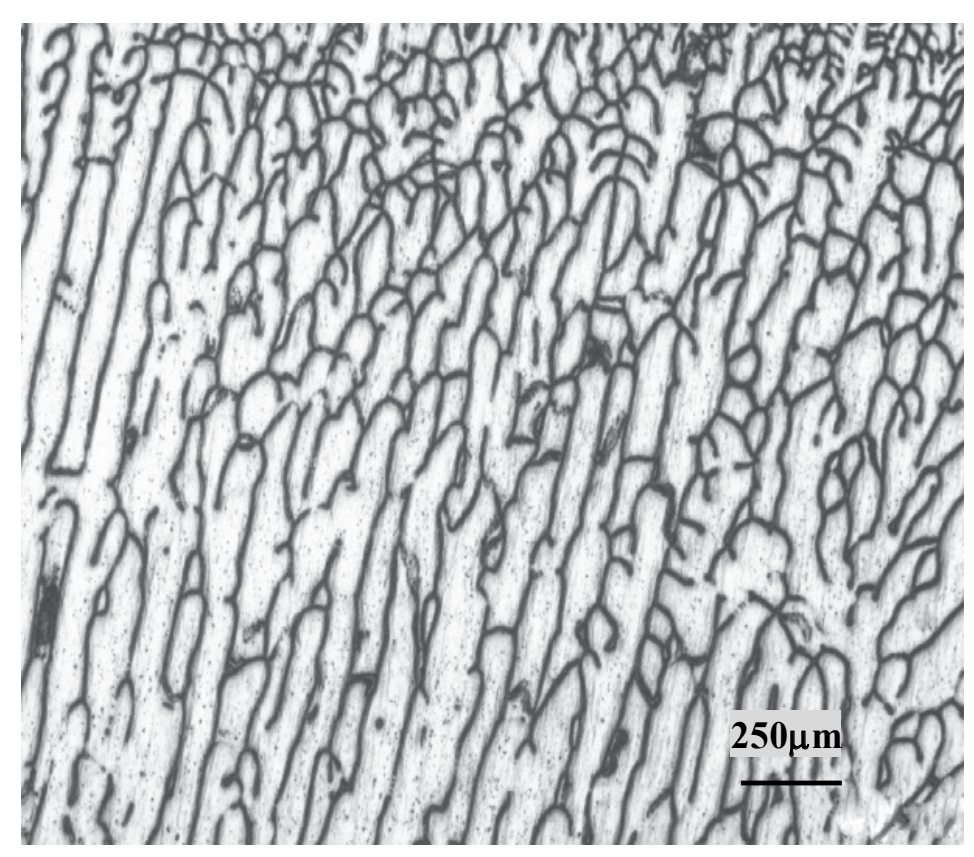

Figure 1: The original microstructure of directionally solidified Mg-4 wt.\% Zn alloy with growth rate of $20 \mu \mathrm{m} / \mathrm{s}$.

cation [16]. Meanwhile, Mg-Zn series alloys have great potential for elevated temperatures workability due to the thermal stability of Mg-Zn phase [17]. In order to raise the applicability, directionally solidified Mg-Zn alloy with outstanding corrosion resistance and good biodegradability is developed in our previous research [18]. But the formability of directionally solidified $\mathrm{Mg}$ alloy is unknown and few researches about hot deformation behavior of directionally solidified $\mathrm{Mg}$ alloy are reported. In the present paper, directionally solidified $\mathrm{Mg}-4 \mathrm{wt} . \%$ $\mathrm{Zn}$ alloy was prepared to investigate the deformation behavior and microstructure evolution via hot compression to provide guidance for biomedical application of directionally solidified Mg alloys.

\section{Material and Methods}

The ingot with nominal composition of $\mathrm{Mg}-4$ wt.\% Zn alloy was prepared by gravity casting. The bars with dimension of $\phi 8 \mathrm{~mm} \times 120 \mathrm{~mm}$ were cut for directional solidification experiment. The growth rate is $20 \mu \mathrm{m} / \mathrm{s}$ and temperature gradient is $13 \mathrm{~K} / \mathrm{mm}$. The detailed experimental process has been described in our previous researches [18-20]. Then, directionally solidified Mg-4 wt.\% $\mathrm{Zn}$ alloy was homogenized at $335{ }^{\circ} \mathrm{C}$ for $16 \mathrm{~h}$, which was acquired in the previous study [21].

Hot compression experiments were carried out on Gleeble 3800 instrument. The testing samples $(\phi 6 \mathrm{~mm} \times 9 \mathrm{~mm}$ ) were wire-electrode cut along the growth direction. The testing tem- perature $(T)$ was $150{ }^{\circ} \mathrm{C} \sim 300{ }^{\circ} \mathrm{C}$ with an interval of $50^{\circ} \mathrm{C}$ and the strain rates $(\dot{\varepsilon})$ were $0.01 \mathrm{~s}^{-1}, 0.1$ $\mathrm{s}^{-1}, 1 \mathrm{~s}^{-1}$ and $10 \mathrm{~s}^{-1}$, respectively. Before the compression test, samples were subjected to heat preservation for 3 minutes and the heating rate was $5{ }^{\circ} \mathrm{C} / \mathrm{s}$, then was deformed with the height reduction of $60 \%$. The deformed specimens were quenched in water immediately after the tests in order to retain the deformed microstructures. The deformed samples were cut along the compression axis for microstructure observation. The microstructure was observed by optical microscope (OM) and scanning electron microscopy (SEM) after polished and etched with a solution of $4.2 \mathrm{~g}$ picricacid $+10 \mathrm{~mL}$ water $+10 \mathrm{~mL}$ aceticacid $+70 \mathrm{~mL}$ ethanol.

\section{Results and Discussion}

\section{Flow stress behavior}

The microstructure of directionally solidified Mg-4 wt.\% Zn alloy is columnar as shown in Figure 1 and the formation mechanism was discussed at length in the previous study [20]. The true stressstrain curves obtained from hot compression experiments are shown in Figure 2. As can be seen from the curves, the stress increases sharply with increase of strain at the initial deformation stage and reaches the peak stress, and then decreases gradually to a steady state. As the previous reports pointed out that the tendency of stress varies with strain is a typical feature of dynamic recrystalliza- 

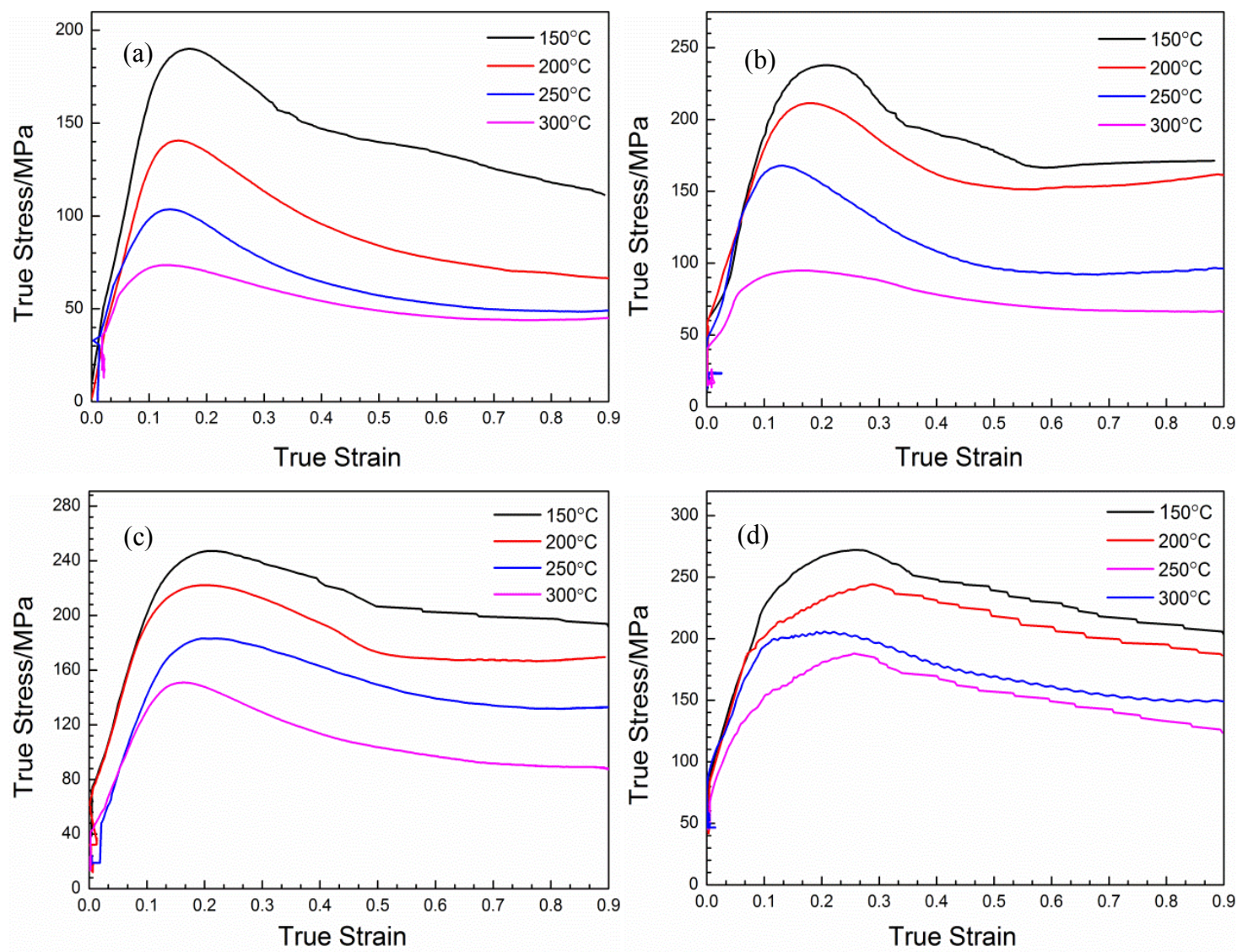

Figure 2: True stress-strain curves at different deformation temperatures with strain rates: a) $0.01 \mathrm{~s}^{-1}$; b) 0.1 $\mathrm{s}^{-1}$; c) $1 \mathrm{~s}^{-1}$ and d) $10 \mathrm{~s}^{-1}$.

tion [22]. At the initial deformation stage, stress increase sharply with strain up to the peak stress, which result from the high density of dislocation at the grain boundaries. As the strain increases, the weaken effect caused by dynamic recrystallization become significant and stress decreases gradually. Besides, it can be seen from Figure 2 that the variation trend between stress and strain mentioned above does not affect by deformation temperature. At a fixed strain rate, stress decreases as the temperature elevating. This phenomenon is explained by two reasons: One is that the flexibility of grain boundaries, atoms and dislocation enhance [23]; the other is that critical resolved shear stress of non-basal slip decreases with increase of deformation temperature [24].

The feature of the curves indicates occurrence of dynamic recrystallization and also implies that the flow stress is sensitive to the strain rate and deformation temperature. Compared with the reported research, directionally solidified $\mathrm{Mg}-4$ wt.\% $\mathrm{Zn}$ alloy in this paper yields higher stress compared with Mg-Y alloy performed by Kula [25], which is mainly contributed to the original microstructure. The grain of directionally solidified alloy is columnar as shown in Figure 1. Thus, coordination between adjacent grains become poor, which is not conductive to the activating of slip systems and results in the higher stress.

\section{Hot deformation behavior}

Hot compression is an effective method to deduce the relationship of flow stress $(\sigma)$ with strain rate $(\dot{\varepsilon})$ and deformation temperature $(T)$, understand the deformation mechanism and obtain the other related parameters, such as deformation activation energy $(Q)$, stress exponent $(n)$ and Zener-Hollomon parameters ( $Z$ ). The relationship between $\sigma$ and $\dot{\varepsilon}$ can be described by three different constitutive equations depending on stress levels.

At the low stress level:

$\dot{\varepsilon}=A_{1} \sigma^{n_{1}} \exp (-\mathrm{Q} / R T)$

At high stress level:

$\dot{\varepsilon}=A_{2} \exp (\rho \sigma)(-\mathrm{Q} / R T)$

For all the stress level: 

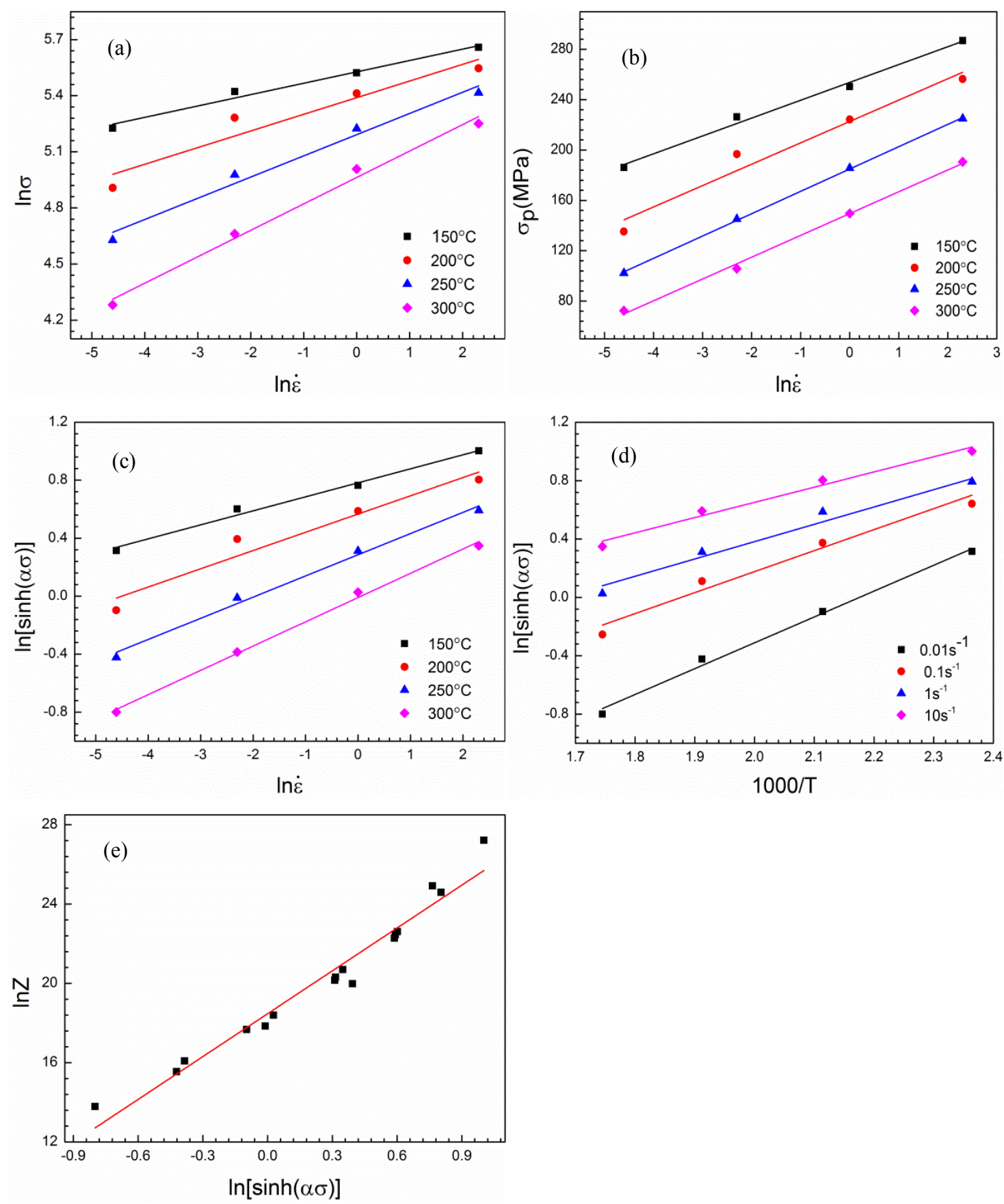

Figure 3: Relationships among peak stress, strain rate and temperature: a) $\ln \sigma_{p}-\ln \dot{\varepsilon} ;$ b) $\left.\left.\sigma_{p}-\ln \dot{\varepsilon} ; \mathrm{c}\right) \ln \left[\sinh \left(\alpha \sigma_{p}\right)\right]-\ln \dot{\varepsilon} ; \mathrm{d}\right) \ln \left[\sinh \left(\alpha \sigma_{p}\right)\right]-1 / \mathrm{T}$ and e) $\operatorname{lnZ}-\ln \left[\sinh \left(\alpha \sigma_{p}\right)\right]$.

$$
\dot{\varepsilon}=A[\sinh (\alpha \sigma)]^{n} \exp (-\mathrm{Q} / R T)
$$

Where, $R$ is gas constant, $A, \alpha, b, n$ and $n_{1}$ are material constants. In order to obtain the values of these constants, natural logarithm is taken on both sides of Eq. (1) Eq. (3). Thus, these equations can be expressed as follows:

$$
\begin{aligned}
& \ln \varepsilon=\ln A_{1}+n_{1} \ln \sigma_{\rho}-\mathrm{Q} / R T \\
& \ln \varepsilon=\ln A_{2}+\beta \sigma_{\rho}-\mathrm{Q} / R T
\end{aligned}
$$

$$
\dot{\ln \varepsilon}=\ln A+n \ln \left[\sinh \left(\alpha \sigma_{p}\right)\right]-\mathrm{Q} / R T
$$

Thus, the value of $n_{1}, b$ and $n$ can be obtained from the mean slope of $\ln \sigma_{p}-\ln \dot{\varepsilon}, \sigma_{p}-\ln \dot{\varepsilon}$ and $\ln [\sin -$ $\left.\mathrm{h}\left(\alpha \sigma_{p}\right)\right]-\ln \dot{\varepsilon}$ according to Figure $3 \mathrm{a}$, Figure $3 \mathrm{~b}$ and Figure 3c. Therefore, $n_{1}=10.895, b=0.0609, n=$ 7.7779 and $\alpha=6 / n_{1}=0.0061$.

According to Eq. (6), deformation activation energy $Q$ can be defined as following: 


$$
\mathrm{Q}=R\left\{\frac{\partial \ln \varepsilon}{\partial \ln \left[\sinh \left(\alpha \sigma_{p}\right)\right]}\right\}_{T}\left\{\frac{\partial \ln \left[\sinh \left(\alpha \sigma_{p}\right)\right]}{\partial(1 / T)}\right\}_{\dot{\varepsilon}}
$$

The mean value of $Q$ can be obtained from the slope of $\ln \left[\sinh \left(\alpha \sigma_{p}\right)\right]-\ln \dot{\varepsilon}$ and $\ln \left[\sinh \left(\alpha \sigma_{p}\right)\right]-1 / T$ as shown in Figure $3 c$ and Figure $3 d$. The mean value of $Q$ is $90.627 \mathrm{~kJ} / \mathrm{mol}$.

The relationship among Zener-Hollomon parameter $(Z)$, strain rate $(\dot{\varepsilon})$ and temperature $(T)$ can be represented as Eq. (8) and Eq. (9).

$$
\begin{aligned}
& Z=\dot{\varepsilon} \exp (\mathrm{Q} / R T)=A\left[\sinh \left(\alpha \sigma_{p}\right)\right]^{n} \\
& \ln Z=\ln A+n \ln \left[\sinh \left(\alpha \sigma_{p}\right)\right]
\end{aligned}
$$

According to Eq. (9), the value of $\ln A$ can be obtained from the intercept of fitted line, which is exhibited in Figure $3 e$.

Finally, the hot compression constitutive equation for directionally solidified Mg-4 wt.\% Zn alloy is acquired as follows:
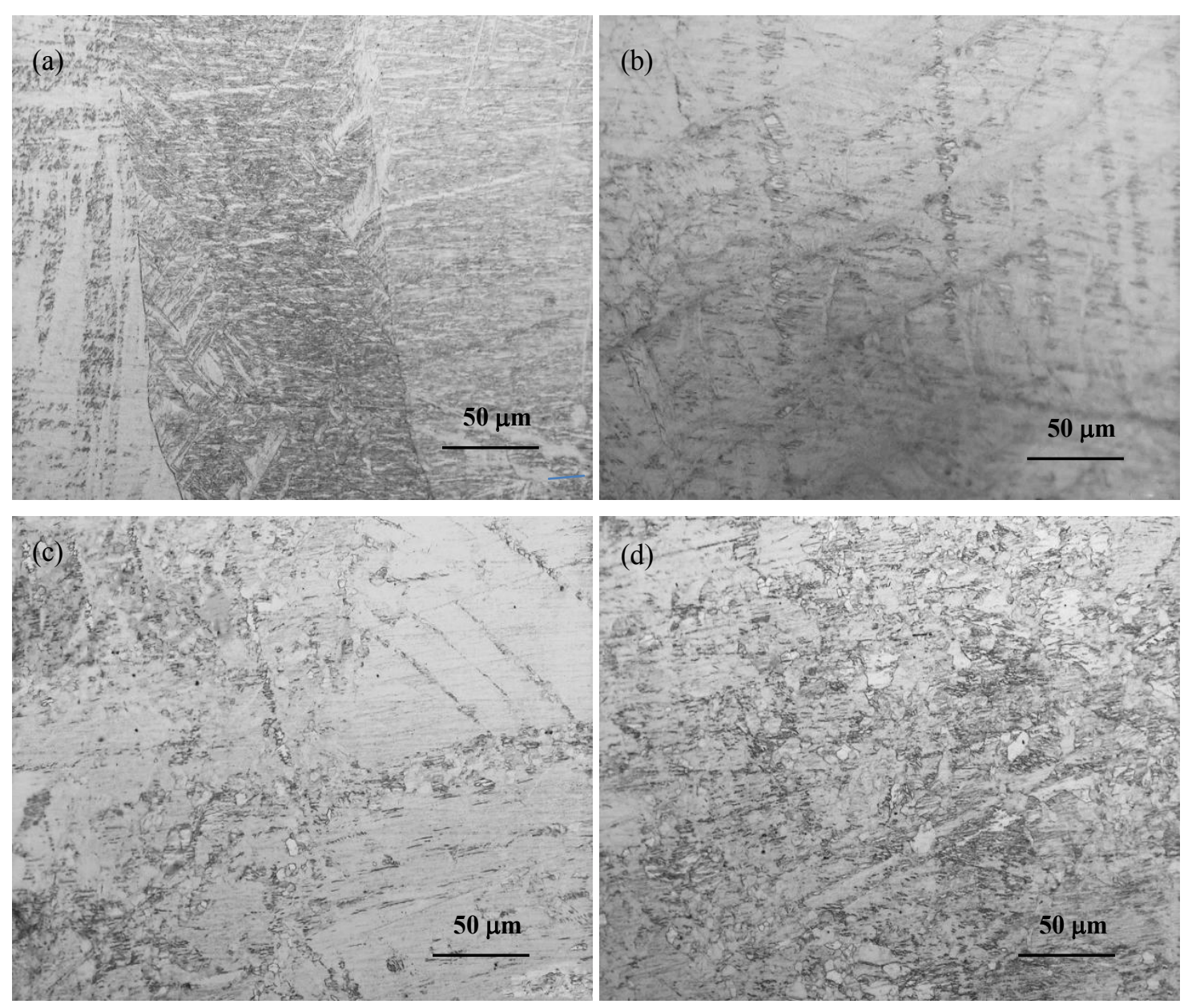

Figure 4: Optical microstructures of directionally solidified $\mathrm{Mg}-4 \mathrm{wt} . \% \mathrm{Zn}$ alloy deformed at a strain rate of 0.1 $\mathrm{s}^{-1}$ under different temperatures: a) $150^{\circ} \mathrm{C}$; b) $200^{\circ} \mathrm{C}$; c) $250{ }^{\circ} \mathrm{C}$ and d) $300^{\circ} \mathrm{C}$. $\dot{\varepsilon}=1.049 \times 10^{8}[\sinh (0.006 \sigma)]^{7.778} \exp \left(-1.091 \times 10^{4} / T\right)$

\section{Microstructure evolution}

The deformed microstructure of directionally solidified Mg-4 wt.\% $\mathrm{Zn}$ alloy at a strain rate of 0.1 $\mathrm{s}^{-1}$ are shown in Figure 4 to illuminate the effect of deformation temperature. It can be seen that the directionally solidified sample has undergone plastic deformation and the columnar grains are filled with large number of twins at $150{ }^{\circ} \mathrm{C}$ (Figure 4a). As the deformation temperature increases to 200 ${ }^{\circ} \mathrm{C}$, fine recrystallization grains are generated and "necklace" structure occurs at the grain boundary and twins, which is shown in Figure $4 b$. The area fraction of recrystallized grains increases when deformation temperature rises to $250{ }^{\circ} \mathrm{C}$ and $300^{\circ} \mathrm{C}$, as shown in Figure 4c and Figure $4 \mathrm{~d}$.

Figure 5 shows the deformation microstructures of directionally solidified Mg-4 wt.\% Zn alloy at $250^{\circ} \mathrm{C}$ to analyze the effect of strain rates. It can be found that fine recrystallized grains are 

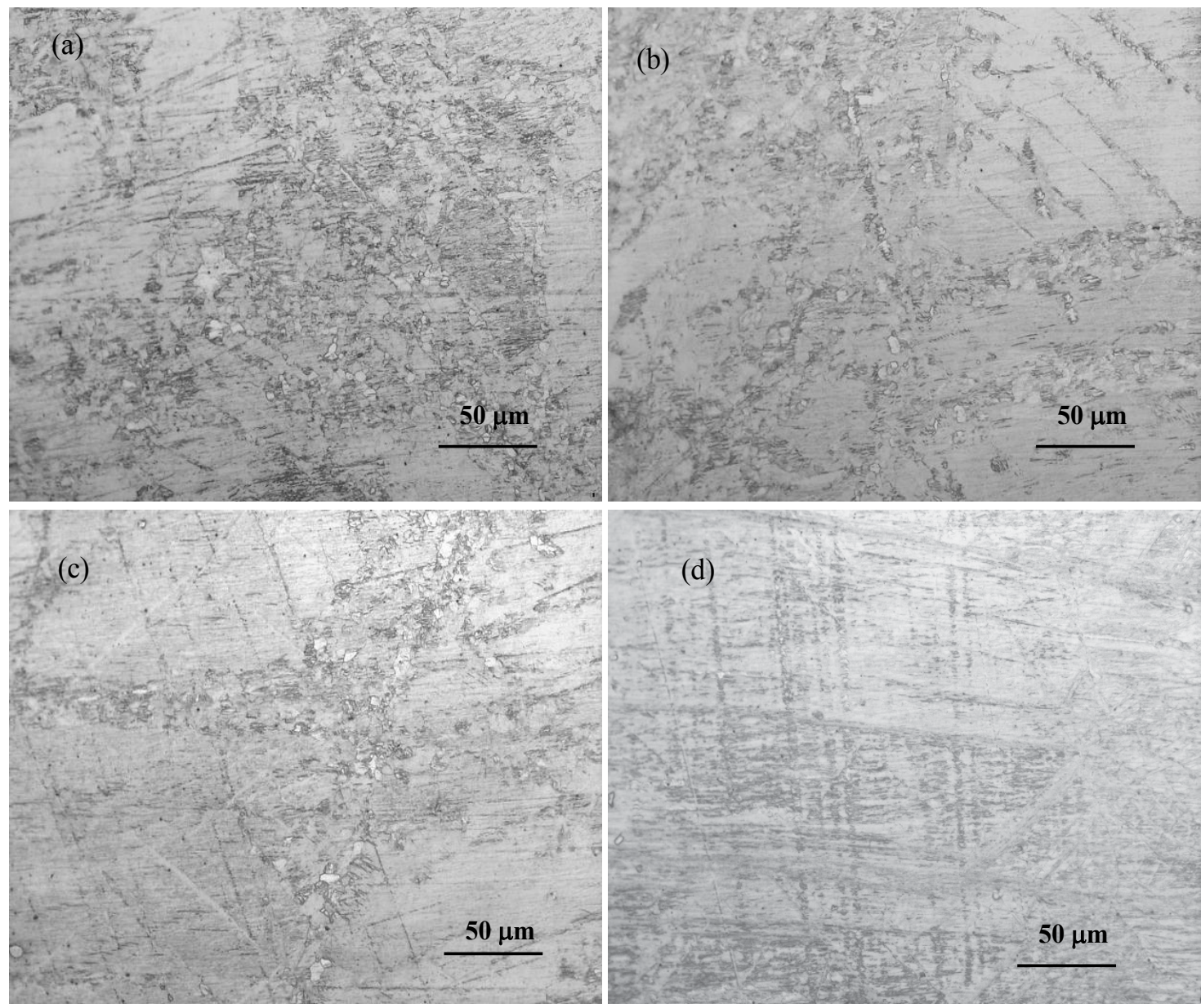

Figure 5: Optical microstructures of directionally solidified Mg-4 wt.\% Zn alloy deformed at the $250{ }^{\circ} \mathrm{C}$ with different strain rates: a) $0.01 \mathrm{~s}^{-1}$; b) $0.1 \mathrm{~s}^{-1}$; c) $1 \mathrm{~s}^{-1}$ and d) $10 \mathrm{~s}^{-1}$.

generated at all strain rates, but the area fraction of the recrystallized grains decreases as strain rate increases.

Based on the above microstructure observation, higher deformation temperature and lower strain rate are beneficial to crystallization and the effect of deformation temperature is more obvious than strain rate on the area fraction of crystallization grains. The reason can be explained by Eq. (8), in which Zener-Hollomon parameter (Z) increases exponentially as the increase of deformation temperature and only has linear change with strain rate.

\section{Conclusions}

1. The constitutive equation of directionally solidified Mg-4 wt.\% $\mathrm{Zn}$ alloy for hot deformation is: $\dot{\varepsilon}=1.049 \times 10^{8}[\sinh (0.006 \sigma)]^{7.778} \exp \left(-1.091 \times 10^{4} / T\right)$.

2. The higher temperature and lower strain rate are beneficial to recrystallization during hot deformation and the effect of hot temperature on the crystallized grain is more obvious.

3. The directionally solidified Mg-4 wt.\% Zn alloy exhibits good hot workability at higher temperature and lower strain rate.

\section{Acknowledgements}

This work was financially supported by the Natural Science Foundation of Shaanxi Province of China (No. 2018JQ5198).

\section{Foundation Item}

Project (2018JQ5198) supported by the Natural Science Foundation of Shaanxi Province of China.

\section{References}

1. BC Suh, MS Shim, KS Shin, NJ Kim (2014) Current issues in magnesium sheet alloys: Where do we go from here? Scripta Materialia 84-85: 1-6.

2. X Fang, S Wu, S Lü, J Wang, X Yang (2017) Microstructure evolution and mechanical properties of quasicrystal-reinforced Mg-Zn-Y alloy subjected to ultra- 
sonic vibration. Materials Science and Engineering: A 679: 372-378.

3. SW Xu, K Oh-Ishi, H Sunohara, S Kamado (2012) Extruded Mg-Zn-Ca-Mn alloys with low yield anisotropy. Materials Science \& Engineering: A 558: 356-365.

4. T Homma, S Hirawatari, H Sunohara, S Kamado (2012) Room and elevated temperature mechanical properties in the as-extruded Mg-Al-Ca-Mn alloys. Materials Science \& Engineering A 539: 163-169.

5. N Erdmann, N Angrisani, J Reifenrath, A Lucas, F Thorey, et al. (2011) Biomechanical testing and degradation analysis of $\mathrm{MgCa0.8}$ alloy screws: A comparative in vivo study in rabbits. Acta Biomaterialia 7: 14211428.

6. C Hampp, N Angrisani, J Reifenrath, D Bormann, JM Seitz, et al. (2013) Evaluation of the biocompatibility of two magnesium alloys as degradable implant materials in comparison to titanium as non-resorbable material in the rabbit. Materials Science and Engineering: C 33: 317-326.

7. C Janning, E Willbold, C Vogt, J Nellesen, A Meyer-Lindenberg, et al. (2010) Magnesium hydroxide temporarily enhancing osteoblast activity and decreasing the osteoclast number in peri-implant bone remodeling. Acta Biomaterialia 6: 1861-1868.

8. Z Li, X Gu, S Lou, Y Zheng (2008) The development of binary Mg-Ca alloys for use as biodegradable materials within bone. Biomaterials 29: 1329-1344.

9. Y Chen, Z Xu, C Smith, J Sankar (2014) Recent advances on the development of magnesium alloys for biodegradable implants. Acta Biomaterialia 10: 4561-4573.

10.YF Zheng, XN Gu, F Witte (2014) Biodegradable metals. Materials Science and Engineering: R: Reports 77: 1-34.

11.MP Staiger, AM Pietak, J Huadmai, G Dias (2006) Magnesium and its alloys as orthopedic biomaterials: A review. Biomaterials 27: 1728-1734.

12.N Stanford, D Atwell, A Beer, C Davies, MR Barnett (2008) Effect of microalloying with rare-earth elements on the texture of extruded magnesium-based alloys. Scripta Materialia 59: 772-775.

13.SZ Zhu, TJ Luo, TA Zhang, YS Yang (2015) Hot deformation behavior and processing maps of as-cast Mg-
$8 \mathrm{Zn}-1 \mathrm{Al}-0.5 \mathrm{Cu}-0.5 \mathrm{Mn}$ alloy. Transactions of Nonferrous Metals Society of China 25: 3232-3239.

14.XP Lin, TB Zhao, Y Dong, J Ye, ZB Fan, et al. (2017) Room-temperature tensile properties of a directionally solidified magnesium alloy and its deformation mechanism dominated by contraction twin and double twin. Materials Science \& Engineering A 700: 681-689.

15.D Vojtěch, J Kubásek, J Serák, P Novák (2011) Mechanical and corrosion properties of newly developed biodegradable Zn-based alloys for bone fixation. Acta Biomaterialia 7: 3515-3522.

16.S Zhang, X Zhang, C Zhao, J Li, Y Song, et al. (2010) Research on an Mg-Zn alloy as a degradable biomaterial. Acta Biomaterialia 6: 626-640.

17.Z Zhang, A Couture, A Luo (1998) An investigation of the properties of Mg-Zn-Al alloys. Scripta Materialia 39: 45-53.

18. H Jia, X Feng, Y Yang (2017) Microstructure and corrosion resistance of directionally solidified $\mathrm{Mg}-2$ wt.\% Zn alloy. Corrosion Science 120: 75-81.

19.HM Jia, XH Feng, YS Yang (2015) Microstructure of directionally solidified Mg-Zn alloy with different growth rates. Materials Science Forum 816: 411-417.

20.HM Jia, XH Feng, YS Yang (2017) Microstructure evolution and growth orientation of directionally solidified Mg-4 wt\% Zn alloy with different growth rates. Acta Metallurgica Sinica 30: 1185-1191.

21.H Jia, X Feng, Y Yang (2015) Influence of solution treatment on microstructure, mechanical and corrosion properties of Mg-4Zn alloy. Journal of Magnesium and Alloys 3: 247-252.

22.J Wang, R Liu, T Luo, Y Yang (2013) A high strength and ductility Mg-Zn-Al-Cu-Mn magnesium alloy. Materials \& Design 47: 746-749.

23.J Buha, T Ohkubo (2008) Natural aging in Mg-Zn(-Cu) alloys. Metallurgical and Materials Transactions $A$ 39: 2259.

24.SR Agnew, Ö Duygulu (2005) Plastic anisotropy and the role of non-basal slip in magnesium alloy AZ31B. International Journal of Plasticity 21: 1161-1193.

25.A Kula, X Jia, RK Mishra, M Niewczas (2017) Flow stress and work hardening of $\mathrm{Mg}-\mathrm{Y}$ alloys. International Journal of Plasticity 92: 96-121. 